\title{
Load testing of Highway Bridge
}

\author{
Petra Bujňákovád ${ }^{1, *}$, Jozef Jošt ${ }^{1}$, and Matúš Farbák ${ }^{1}$ \\ ${ }^{1}$ University of Žilina, Department of Structures and Bridges, Univerzitná 8215/1, Slovakia
}

\begin{abstract}
New segmental concrete bridge has been built near the city Žilina, aligned on European highway corridor E 50. The bridge is composed of the two separate precast prestressed box girder structure constructed by balanced cantilever method. The total length of both structures is $1042 \mathrm{~m}$. The similar superstructure consists of a total of eighteen continuous spans with main spans of $60.5 \mathrm{~m}$. The construction process, load carrying capacity and monitoring of the bridge has been investigated before the opening of the bridge. The paper presents verification of the structural behaviour of the bridge under static load compared to predicted model for both precast prestressed structures.
\end{abstract}

\section{Introduction}

The use of precast concrete box girder was chosen as the flexible system and appropriate method in a municipal zone. One advantage of this technique is elimination of conventional falsework and temporary supports by adopting cantilever construction method. The major part of the work is performed in the precasting yard and erection process can start simultaneously with the foundation work. During the construction process, the structure changes in static system, in support, loading and magnitude of external prestressing. The whole section remains in compression under both dead and live load. An accurate evaluation of stresses and deformation in each construction stage is essential to maintain safety levels and to ensure the final required bridge alignment. Before the serviceability of the bridge system, The Slovak standard codes recommended a static load test for any new bridge exceeding $18 \mathrm{~m}$ and a dynamic load test for bridge span over the $45.0 \mathrm{~m} \mathrm{[9].} \mathrm{Load}$ testing of bridges allows to investigate the real behaviour of structure under short-term loading. Bridge monitoring is a complement to a load testing. It could detect the abnormal behaviour during construction stage, service period and deterioration of the bridge. Structural changes may result from other causes such as sudden settlement of foundation, ground movement, excessive traffic or failure of post-tensioning tendons [4]. To avoid the unpredictable structural changes both bridge superstructures were monitored. The data have been collected continuously during the fabrication and erection process in 2016 and 2017. The static and dynamic test (right bridge) was performed in November, 2017. These data can be used to check future condition of the bridge in relation to the initial condition.

\footnotetext{
* Corresponding author: petra.bujnakova@,fstav.uniza.sk
} 


\section{Bridge load testing}

The load test was performed by Department of Structures and Bridges (University of Žilina) in collaboration with the Accredited Laboratory of Civil Engineering at University of Žilina. Measurement of the right and left bridge has been carried out so as to achieve the greatest loading effect for selected spans of the bridge superstructure. The measured quantities were compared with the corresponding values obtained from the theoretical calculation achieved using FE model to determine the actual behaviour of the bridge structure. During the test, strain and vertical deflection were measured and recorded by the host computer. The bearing movement was geodetically controlled. The temperature of structure and also ambient temperature was registered.

\subsection{Bridge description}

The segmental bridge is a part of the new Slovak highway connection from Bratislava to the Ukrainian border forming the international connection E 50, located in the urban area of village "Lietavská Lúčka" near the city Žilina. The bridge is composed of the two separate precast concrete structure. The both superstructure consists of a total of eighteen continuous spans with lengths $46.10+15 \times 60.50+49.80+32.80 \mathrm{~m}$, Fig. 1 . The balanced cantilever method, with the self-launching gantry was used for erection. The shorter end spans, adjacent to the abutment, had to be built by employing falsework. The posttensioned structure is made of individual precast units stressed together. The joints are made of a very thin epoxy resin. To lock the segments together the shear keys are cast into the joint faces.

The roadway has a variable width from 11.75 to $13.25 \mathrm{~m}$ between barriers and the total deck width varying from 14.25 to $15.75 \mathrm{~m}$. The typical cross section consists of posttensioned box girders of the constant depth $3.0 \mathrm{~m}$ for all the spans providing the most efficient section for casting, Fig. 2. The span- to- depth ratio is corresponding to 20. Pier and abutment segments are $1.65 \mathrm{~m}$ in length, the span segments are $2.2 \mathrm{~m}$ long. The span segments were designed of concrete class C 45/55 and pier segments of C 55/67. The typical cross section is shown in Figure 2. The constant web thickness $500 \mathrm{~mm}$ was determined by shear considerations, as tendon ducts internal to the concrete were present. Box girder webs are inclined. The local haunches are used at the intersection of the bottom slab and the webs to provide sufficient space for accommodating the required number of tendons. The box segment has a bottom slab width of $6.5 \mathrm{~m}$. The bottom flanges are 200 $\mathrm{mm}$ and $350 \mathrm{~mm}$ thick. The top slab thickness is variable, resulted from the limit deflection criteria under the live loading. The superstructure is prestressed by bonded prestressing tendons of $15.7 \mathrm{~mm}$ diameter strand.
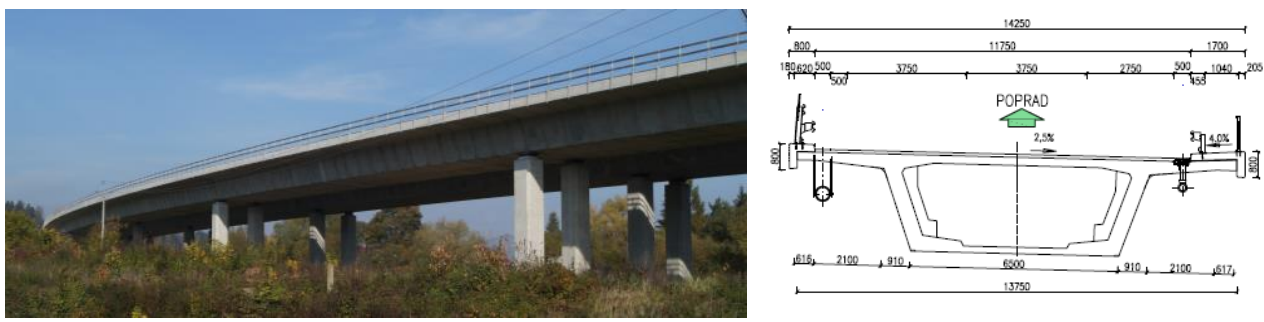

Fig. 1. View on the bridge

Fig. 2. Cross section of the bridge 


\subsection{Modelling and Analysis}

The representative fine element model (FEM) was created to investigate the structural behaviour of both prestressed bridges under loads. The bridge structure was created as a continuous box girder structure in computing program Scia Engineer, Fig.3. Bridge geometry has been taken from the technical report [1], [2]. As an input material characteristics, the experimentally determined values of compressive strength and modulus of elasticity of concrete were used. All specimens were tested in Accredited Laboratory of Civil Engineering at University of Žilina [3].

The concrete specimens were gained during the segment erection in the stationary yard and during the concreting of closure joint at the construction site. The compressive strength as the common performance property was measured by breaking cube concrete specimens of $150 \mathrm{~mm}$ size in the laboratory. The average achieved concrete strength was $74.8 \mathrm{MPa}$ for segments near the pier and for the concrete closing joint at the mid- span was $66.8 \mathrm{MPa}$ ( $3 \times 3$ specimens). The actual modulus of elasticity of the concrete is a determinant parameter for the bridge deflection. The average static modulus of elasticity obtained from testing was $42.7 \mathrm{GPa}(3 \times 3$ samples, $\phi 150 \times 300 \mathrm{~mm})$. For better determining of the modulus of elasticity the non-destructive method was used. The ultrasonic measurements were made on the $3 \times 3$ samples with size of $\phi 150 \times 300 \mathrm{~mm}$. The average value was $41.07 \mathrm{GPa}$.

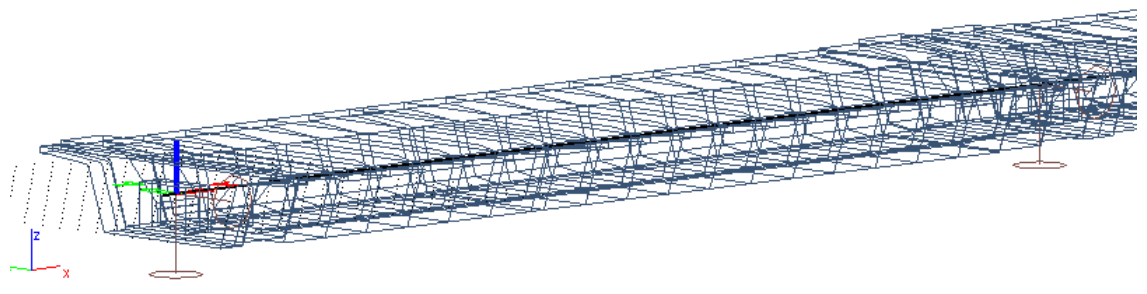

Fig. 3. FE model of the bridge superstructure

\subsection{Load test procedure}

The load testing procedure and the type of instrumentation used for both bridges were essentially the same. The strain gauges, deflection gages and acceleration gages were installed at specified locations for the testing.

Four strain gauges according to Figure 4 were installed at the intersection of the slabs and the webs of cross sections. A total of 16 strain gauges were placed on the left bridge (span no. 7 and no. 16) and the 16 strain gauges on the right bridge (span no. 2 and no. 9). The selected segments of the right bridge were implemented with strain gauges during the erection process. The strain gauges were installed in the mid- span on the closure joint (Figure 4) and near the pier segment (Figure 5). For strain time dependent variation of the left bridge, the vibrating wire strain gauges, suitable for long term readings were placed in the pier segment during casting in the stationary yard (Figure 6) and in the closure joint before concreting in- situ (Figure 7).

Vertical deflections were measured with linear displacement tranducers. The seven selected spans were measured on the each bridge. The measurement points are installed at the left and at the right bottom side of the cross section at the mid - span. The movement of the bridge superstructure over the bearings were verified at two points. Temperature measurements (ambient and structure) were made on the specified 32 different locations across the centre of the span and pier sections The other signs such as cracking were controlled during the testing. 
The testing apparatus for static load test was designed as follows, 4 testing vehicles on the first span and end span. Main fields $(60.5 \mathrm{~m})$ consist of 6 testing vehicles. The maximum weight of the 4 -axle vehicle required for a load test was 42.0 t. The vehicles were placed at the predetermined critical load positions on the bridge structure and strain and deflection were measured.
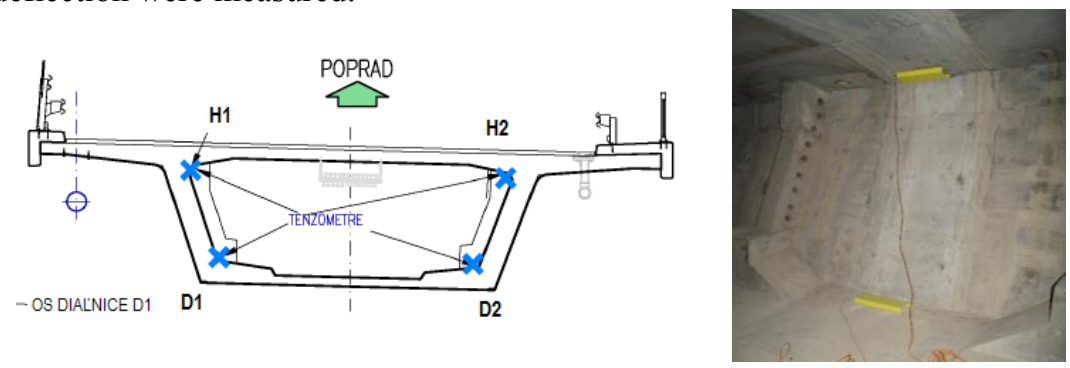

Fig. 4. Right bridge - The strain gages setup - closing joint
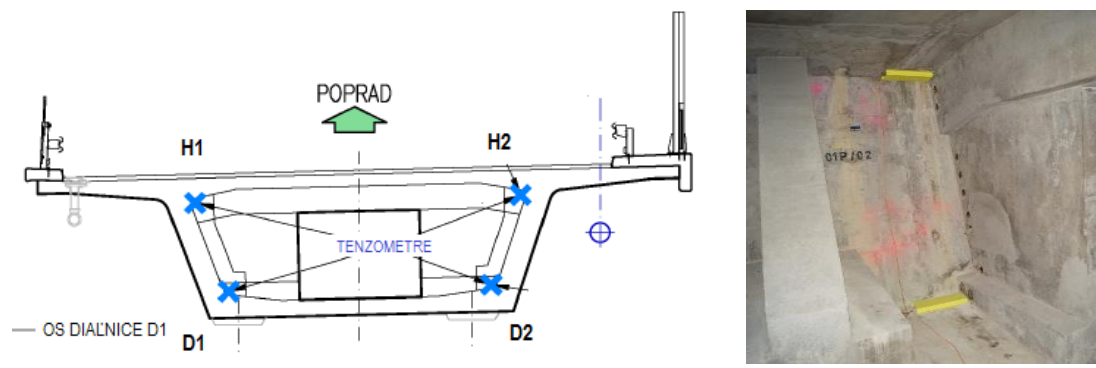

Fig. 5. Right bridge - The strain gages setup near the pier

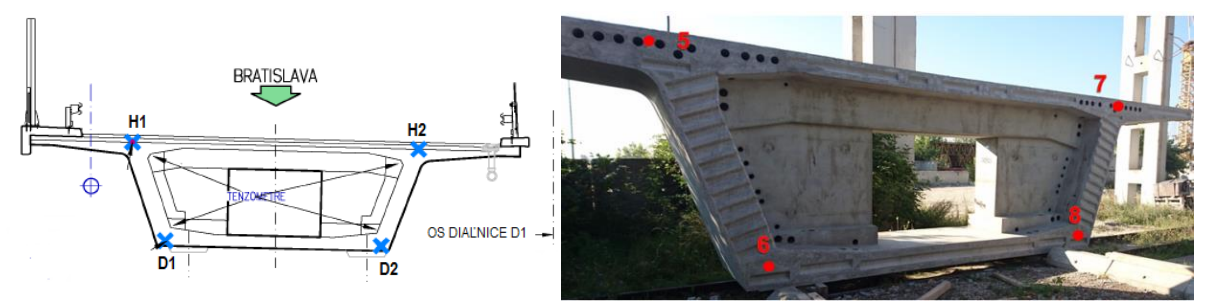

Fig. 6. Left bridge - The strain gages setup - segment casting
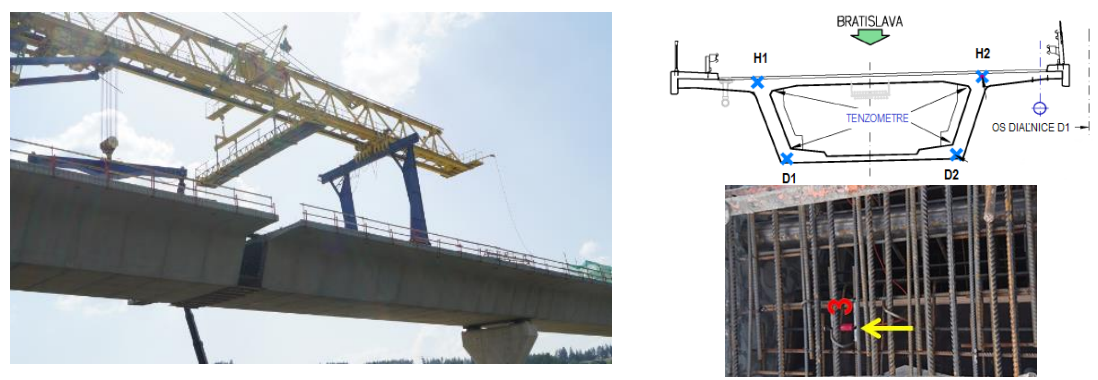

Fig. 7. Left bridge - The strain gages setup - closing joint - during erection

The measurement period of the load effect was 60 minutes and then 60 minutes for unloading. The overall time for static load test of both prestressed box girder structure was taken fifteen hours. The static load efficiency (the ratio of the actual load value to the value 
considered in the calculation) was determined from the values of the vertical deflection at the mid- span according to STN 736209 [9]. Results of comparison between the measured and theoretically estimated deflection of the mid- span for left and right side of prestressed bridges are shown in Figure 8, 9. The maximum residual deflection in the middle of main span of both superstructure was approximately $12.5 \mathrm{~mm}$
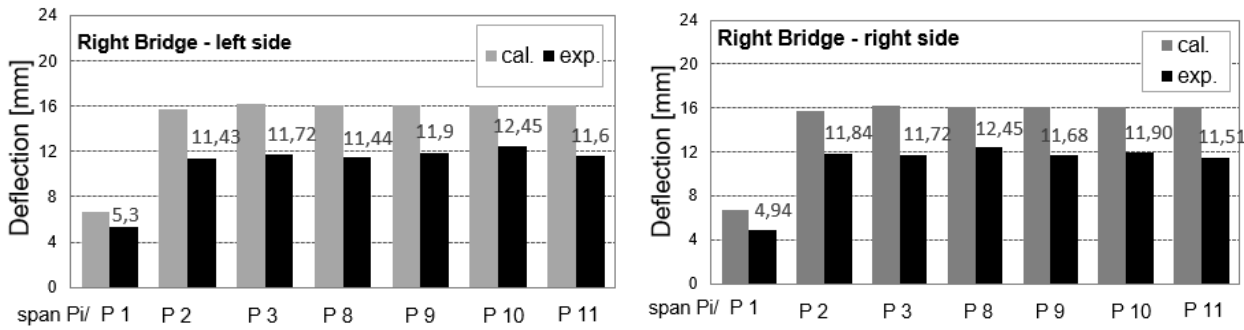

Fig. 8. Deflection of the bridge structure - Right Bridge
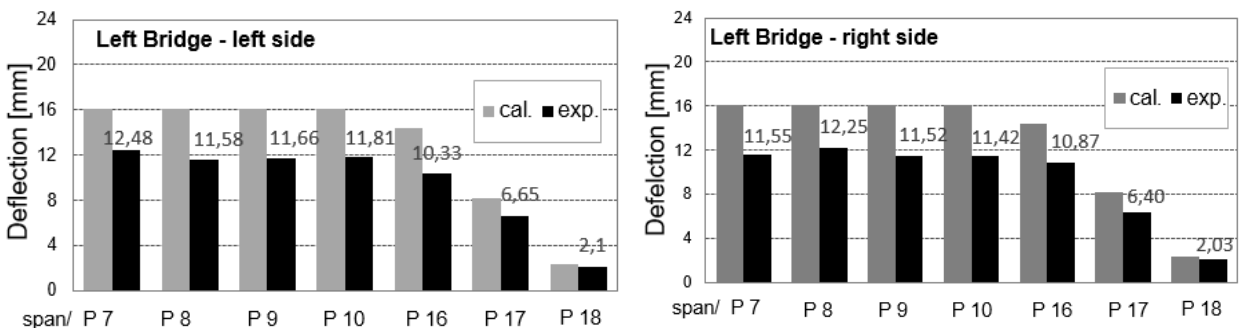

Fig. 9. Deflection of the bridge structure - Left Bridge

Figure 10 illustrates the normal stresses variation in the mid-section of the sixteenth span of the left bridge during the construction stages (in the stage of cantilever, Pnk), before loading (PZS) and in static load test (ZS). The prediction stress distribution and obtained values in bottom and top slab of the cross section achieved acceptable agreement.
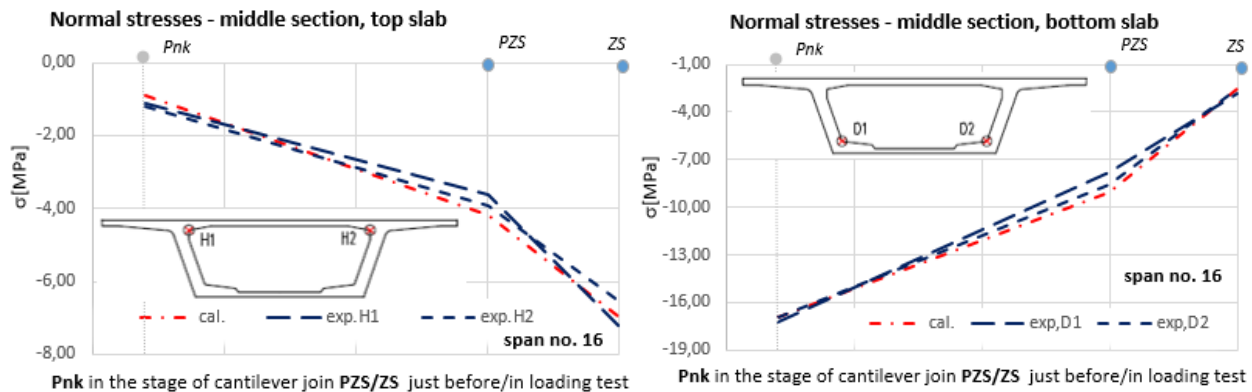

Fig. 10. Normal stress variation (span no.16) - Left Bridge

The dynamic load test of right bridge was conducted with two 4-axle vehicles driven in the centre of the road at constant speed. Testing began at approximately a vehicle speed of $5 \mathrm{~km} / \mathrm{h}$ and then the speed was increased to the $70 \mathrm{~km} / \mathrm{h}$. Tests were repeated with a plank placed on the road in the main measurement cross section (span no. 8). The left bridge (span no. 9) will test in close future. Subsequently the results of dynamic tests, such as natural frequencies, dynamic deflection, damping ratio will show in next paper. 


\section{Conclusions}

Proof loading has indicated that both precast segmental structures have greater strength than predicted by analysis. Neither cracking nor other signs of distress were observed at the applied load. Load efficiency factor was approximately $73 \%$ for the main spans and $88 \%$ for the end spans that meets national standard requirement of 0.7 to 1.05 for concrete bridges according to [9]. Deflection analysis indicate that the bridge structure is in good elastic condition. The actual modulus of elasticity must be known for better interpretation of the load test results. The collected data during the load testing can be used for future condition assessment and will be able to detect any potential failure.

This research work was supported by the Slovak Grant Agency under contract No. 1/0336/15 and No. $1 / 0343 / 18$

\section{References}

1. J. Bujňák, Design review of the right bridge SO 209 at the highway construction D1 Hričovské Podhradie - Lietavská Lúčka (University of Žilina, Slovakia, 07/2015)

2. J. Bujňák, Design review of the left bridge SO 209 at the highway construction D1 Hričovské Podhradie - Lietavská Lúčka (University of Žilina, Slovakia, 11, 2015)

3. J. Bujňák J, P. Bujňáková, Monitoring report of the bridge SO 209 at the highway construction D1 Hričovské Podhradie - Lietavská Lúčka (University of Žilina, Slovakia, 2018)

4. B. Massicotte, A. Picard, PCI Journal, May-June, 66- 80 (1994)

5. M. Hassan, O. Burdet and R. Favre, IABSE Colloquium: Remaining Structural Capacity, Copenhagen, Denmark, March (1993)

6. J. Zhao, T. Liu, Y. Wang, International Conference on Risk and Engineering Management (2011)

7. Design guide: Prestressed concrete bridges built using the cantilever method (Sétra: FR, 2003)

8. Guide to good practice, FIB report: 2017 Precast Segmental Bridges, ISBN 978-288394-122-9, 183 (2017)

9. STN 73 6209: Loading test of Bridges (1979)

10. STN EN 1991-2: 2006 Eurocode 1: Actions on Structures. Part 2: Traffic Loads on Bridges (UNMS, Bratislava, SK)

11. STN EN 1992-2: 2012 Eurocode 2: Design of Concrete Bridges. Design and Detailing Rules (UNMS, Bratislava, SK)

12. STN EN $206+$ A1: 2017 Concrete. Specification, performance, production and conformity (UNMS, Bratislava, SK) 